\title{
Patient-Reported Burden of Illness in a Prevalent COPD Population Treated with Long-Acting Muscarinic Antagonist Monotherapy: A Claims-Linked Patient Survey Study
}

\author{
Beth Hahn (D) - Richard H. Stanford - Alyssa Goolsby Hunter • \\ Breanna Essoi · John White · Riju Ray
}

Received: December 19, 2018 / Published online: April 1, 2019

(C) The Author(s) 2019

\begin{abstract}
Introduction: Symptom burden in inadequately controlled chronic obstructive pulmonary disease (COPD) considerably impacts quality of life, healthcare resource utilization (HCRU) and associated costs. This claims-linked cross-sectional survey study assessed symptom burden and HCRU among a prevalent population of COPD patients prescribed long-acting muscarinic antagonist (LAMA) monotherapy.

Methods: Patients were identified using claims data from the Optum Research Database. Eligible patients were aged $\geq 40$ years with 12 months' continuous enrollment in a US
\end{abstract}

Enhanced digital features To view enhanced digital features for this article go to https://doi.org/10.6084/ m9.figshare.7819946.

Electronic supplementary material The online version of this article (https://doi.org/10.1007/s41030019-0091-0) contains supplementary material, which is available to authorized users.

B. Hahn $(\bowtie) \cdot$ R. H. Stanford

US Value Evidence and Outcomes, GSK, 5 Moore Drive, Research Triangle Park, NC 27709-3398, USA e-mail: beth.a.hahn@gsk.com

A. Goolsby Hunter · B. Essoi · J. White

Health Economics and Outcomes Research, Optum, 11000 Optum Circle, Eden Prairie, MN 55344, USA

R. Ray

US Medical Affairs, GSK, 5 Moore Drive, Research

Triangle Park, NC 27709-3398, USA health plan, $\geq 2$ medical claims containing COPD diagnosis codes $\geq 30$ days apart, and $\geq 2$ claims for LAMA monotherapy in the latter half of the 12-month sample identification period. Patients were mailed a cross-sectional survey assessing patient-reported outcomes (PROs) [COPD assessment test (CAT) and modified medical research council dyspnea scale $(\mathrm{mMRC})]$, clinical characteristics, smoking history, and demographics. Patients also completed the Exacerbations of Chronic Pulmonary Disease Tool (EXACT-PRO) daily diary for 7 days. HCRU was assessed from claims data.

Results: The study included 433 patients with a self-reported healthcare provider COPD diagnosis, and both claims-based and self-reported LAMA monotherapy treatment (mean age 71.0 years; $59.8 \%$ female). Most patients $(85.5 \%)$ reported a high symptom burden (CAT score $\geq 10), 45.5 \%$ had high levels of dyspnea (mMRC grade $\geq 2$ ), and $64.4 \%$ reported more severe daily symptoms by the EXACT-PRO. Most patients (71.6\%) reported high scores on $\geq 2$ PROs. More patients with high symptom burden had COPD-related emergency department visits than those with lower disease burden $(27.6 \%$ vs $12.7 \%, P=0.012)$.

Conclusions: In conclusion, a large proportion of patients with COPD receiving LAMA monotherapy experienced a high symptom burden and may benefit from therapy escalation. Healthcare professionals can use validated PROs to help them assess symptom burden. 
Funding: GlaxoSmithKline (GSK study number: 205862)

Keywords: Bronchodilator agents; COPD; Health surveys; Patient-reported outcomes

\section{INTRODUCTION}

Chronic obstructive pulmonary disease (COPD) is one of the most common chronic diseases, and is a leading cause of mortality and morbidity worldwide $[1,2]$. In the USA, it is the third leading cause of death and is reported to affect over 15 million people [3, 4]. This number is expected to rise due to increasing exposure to risk factors and changing population demographics. COPD, characterized by airflow obstruction that progressively worsens over time, leads to debilitating symptoms such as dyspnea and persistent cough and is one of the leading causes of hospitalizations and emergency department (ED) visits globally $[1,5]$. COPD is also associated with considerable economic burden, with COPD exacerbations in particular contributing significantly to both direct and indirect healthcare costs $[1,2,5]$.

The mainstay of pharmacological therapy for COPD is bronchodilation with a long-acting muscarinic antagonist (LAMA), a long-acting $\beta_{2^{-}}$ agonist (LABA), or a combination of the two [6-8]. Currently, the 2019 Global Initiative for Chronic Obstructive Lung Disease (GOLD) strategy document recommends LAMA or LABA monotherapy as the initial therapy for patients with COPD with a lower symptom burden and higher exacerbation history, and a higher symptom burden and lower exacerbation history [2]. However, a significant proportion of patients can fail to achieve adequate control of symptoms when treated with LAMA or LABA monotherapy [9]. For these patients, escalation to LAMA/LABA combination therapy is recommended, or escalation to triple therapy [a combination of a LAMA, LABA, and inhaled corticosteroid (ICS)] [3] for patients at higher risk of exacerbation $[2,9]$.

The increased symptom burden in patients with inadequately controlled COPD can reduce activity levels and quality of life (QoL) [10-12], as well as increasing the risk and frequency of exacerbations which are associated with more rapid disease progression [13] and are a major driver of healthcare resource utilization (HCRU) and associated costs $[14,15]$. It is therefore important to understand the symptom burden for patients receiving COPD treatment, so that treatment strategies can be optimized.

The objective of this study was to further understand the burden of COPD by examining symptom burden and HCRU among a prevalent population of patients with COPD treated with LAMA monotherapy. The primary objective was to identify the proportion of patients reporting COPD symptoms while receiving treatment with LAMA monotherapy. Secondary objectives included the description of the patient-reported burden of illness, and all-cause and COPDrelated HCRU.

\section{METHODS}

\section{Study Design}

The study was a claims-linked, cross-sectional survey of patients with COPD who were prescribed LAMA monotherapy and enrolled in commercial or Medicare Advantage (MA) insurance plans. Patients were identified using medical and pharmacy claims, and enrollment data from the Optum Research Database (ORD) between October 1, 2015 and September 30, 2016. The ORD is a large, geographically diverse, US administrative claims database. In 2016, approximately 32.8 million individuals with commercial coverage and 3.2 million individuals with MA coverage were included in the ORD.

Patients who met study inclusion/exclusion criteria (below) were recruited directly by mail and consented to study participation by returning a completed paper survey and/or a 7-day daily diary. Survey data collection occurred from October to December 2016 and was conducted using a modified Dillman method [16]. Patients were paid $\$ 25$ following the return of the survey and/or diary with a maximum payment of $\$ 50$ per patient. 
The study was approved by the New England Institutional Review Board (NEIRB), on September 9, 2016 (IRB \#120160900). Data collection activities were initiated following all approvals. All procedures performed in studies involving human participants were in accordance with the ethical standards of the institutional and/or national research committee and with the 1964 Helsinki declaration and its later amendments or comparable ethical standards. Informed consent to take part in the study was implied by the return of study materials.

\section{Patient Identification}

Patients were required to be at least 40 years of age and continuously enrolled in a commercial or MA health plan with both medical and pharmacy benefits during the 12-month baseline period. Patients were also required to have $\geq 2$ medical claims containing diagnosis codes commonly used to define COPD $[2,17]$ [International Classification of Disease 10th Revision Clinical Modification (ICD-10-CM) codes J40-J44] at least 30 days apart during the 12 -month baseline and $\geq 2$ claims for LAMA monotherapy (umeclidinium, tiotropium, or aclidinium) in the latter 6 months of the sample identification period (codes and treatments are presented in Supplementary Table S1). Patients were excluded if they had prescription claims for any ICS- or LABA-containing therapy (ICS, ICS/LABA, or LAMA/LABA) during the 12-month baseline period. Patients with evidence of lung cancer during the baseline period were excluded. All patients were also required to self-report a healthcare professional diagnosis of COPD and LAMA monotherapy use, and to be able to complete the study surveys in English.

\section{Study Measures}

Demographic, sociodemographic, and clinical characteristics were captured using both patient-reported survey data and claims data, including patient-reported time since diagnosis, and smoking status. Claims-based evidence of 11 COPD-related comorbidities were identified: dyspnea; hypertension; atherosclerotic cardiovascular disease (ASCVD); type 2 diabetes mellitus; obstructive sleep apnea; depression; anxiety (all comorbidities were based on diagnosis codes except for depression and anxiety rates, which were based on evidence of diagnosis and/or treatment) [18]. Quan-Charlson comorbidity scores [19] were calculated based on the presence of diagnosis codes on medical claims during the baseline period. HCRU, including ambulatory (physician office and outpatient), inpatient, and ED visits, were obtained from medical claims. HCRU was defined as COPD-related if the medical claim included an ICD-10-CM diagnosis code for COPD in any position.

\section{PRO Measures}

In this study, burden of illness for COPD was defined by symptom burden, dyspnea, and symptom severity, and was assessed using three COPD-related validated patient-reported outcomes (PRO) measures. Symptom burden was assessed using the COPD Assessment Test (CAT) [20] and dyspnea was assessed using the modified medical research council dyspnea scale (mMRC) (both assessed using survey data); symptom severity was measured using the EXACT [21] (assessed using a daily diary for 7 days). The EXACT was used in a time-limited fashion to assess symptoms not addressed by CAT or mMRC, and was not used to evaluate exacerbation history. Classifications of burden of illness, dyspnea, and symptom severity were based on established cut-points, where available: [2] patients with an mMRC score $\geq 2$ (range 0-4) were classified as having severe dyspnea, and patients with a CAT total score $\geq 10$ (range 0-40) were classified as having a high symptom burden [22]. For EXACT scores, patients with more severe symptoms were defined as those having an EXACT score greater than the mean total score in the study sample on at least 1 day. The proportion of patients with CAT, mMRC, and EXACT scores meeting these thresholds were used to show the prevalence of high symptom burden among patients treated with LAMA monotherapy. 


\section{Statistical Analyses}

The analytic population consisted of respondents with claims-linked survey and diary data who met all study inclusion and exclusion criteria $(n=433)$. Statistical analyses were performed using SAS software (SAS Institute Inc., Cary, NC, USA, version 9.4) on a Unix platform. Results are presented descriptively. Statistical comparisons were performed using the appropriate two-sided tests (e.g., $t$-test, chi-square test) based on the distribution of the measure. For all PRO measures, the mean total, summary, and/or domain scores and standard deviations (SDs) were calculated. In all analyses, statistical significance was defined as $P<0.05$.

\section{RESULTS}

\section{Study Population}

A total of 2275 patients met the eligibility criteria for the study [including having multiple medical claims containing COPD diagnosis codes (Supplementary Table S1), a self-reported healthcare provider COPD diagnosis, and both claims-based and self-reported LAMA monotherapy treatment] and were invited to participate. Of these, 528 completed the survey and daily diary $(29.8 \%$ response rate [23]) and 433/528 had matched claims, survey, and diary data, and were included in the final analyses (Fig. 1).

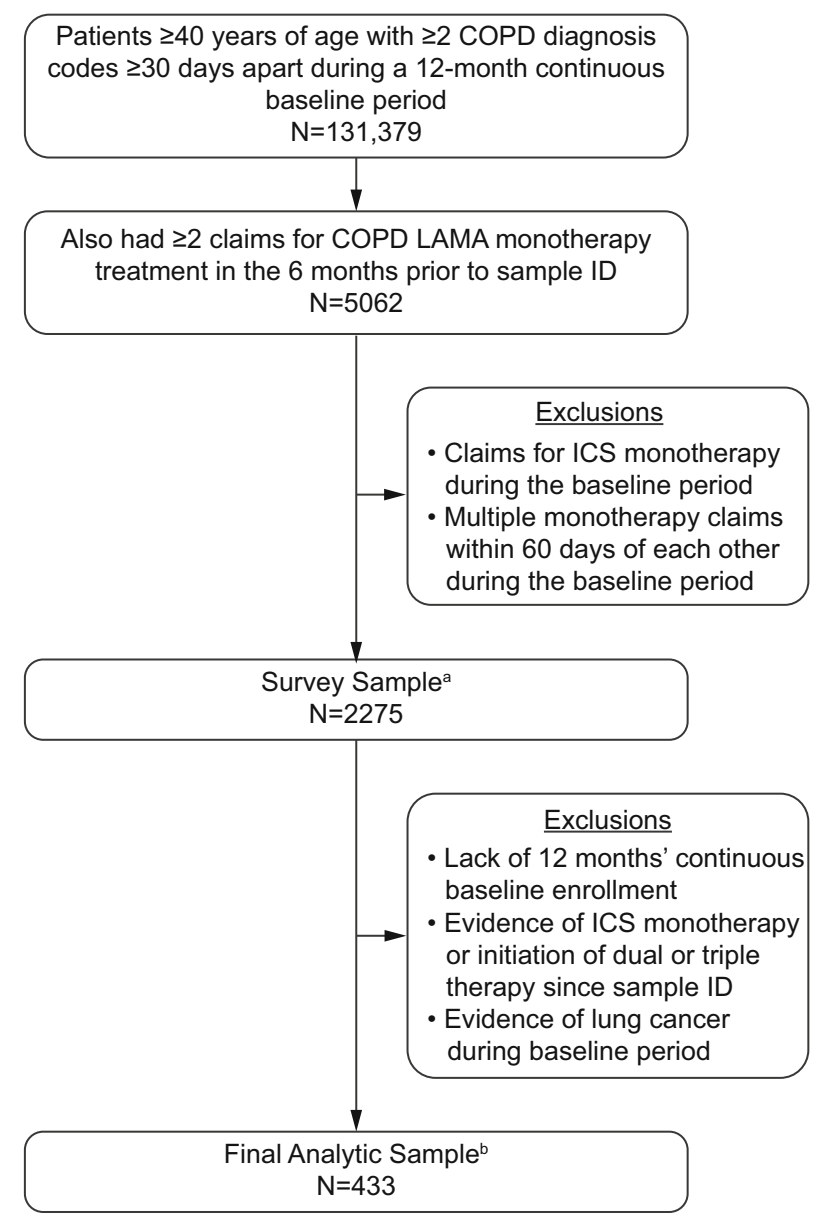

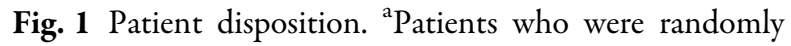
chosen and invited to participate in the survey study by mail; ${ }^{\mathrm{b}}$ patients with matched claims, survey, and diary data.
COPD chronic obstructive pulmonary disease; ICS inhaled corticosteroid; ID identification; LAMA long-acting muscarinic antagonist 
Table 1 Demographic, sociodemographic, and clinical characteristics

\begin{tabular}{|c|c|}
\hline & $\begin{array}{l}\text { Total } \\
(n=433)\end{array}$ \\
\hline $\operatorname{Age}^{\mathrm{a}}$, mean $(\mathrm{SD})$ & $71.0(9.4)$ \\
\hline Female $^{\mathrm{a}}, n(\%)$ & $259(59.8)$ \\
\hline \multicolumn{2}{|l|}{ Insurance type ${ }^{\mathrm{b}}, n(\%)$} \\
\hline Commercial & $51(11.8)$ \\
\hline Medicare advantage & $382(88.2)$ \\
\hline \multicolumn{2}{|l|}{$\operatorname{Race}^{\mathrm{a}, \mathrm{c}}, n(\%)$} \\
\hline Black or African American & $31(7.2)$ \\
\hline White & $375(86.8)$ \\
\hline \multicolumn{2}{|l|}{ Education level $^{\mathrm{a}}, n(\%)$} \\
\hline High school or less & $247(58.4)$ \\
\hline College/graduate school & $176(41.6)$ \\
\hline Missing & 10 \\
\hline \multicolumn{2}{|l|}{ Household income $^{\mathrm{a}}, n(\%)$} \\
\hline$<\$ 50,000$ & $339(79.2)$ \\
\hline$\geq \$ 50,000$ & $48(11.2)$ \\
\hline Declined to answer & $41(9.6)$ \\
\hline Missing & 5 \\
\hline \multicolumn{2}{|l|}{ Time since COPD diagnosis ${ }^{\mathrm{a}}, n(\%)$} \\
\hline$\leq 5$ years & $226(52.4)$ \\
\hline$>5$ years & $205(47.6)$ \\
\hline Missing & 2 \\
\hline $\begin{array}{l}\text { Quan-Charlson comorbidity score }{ }^{\mathrm{b}} \\
\text { mean (SD) }\end{array}$ & $2.2(1.6)$ \\
\hline \multicolumn{2}{|l|}{ COPD-related comorbidities ${ }^{\mathrm{b}, \mathrm{d}}, n(\%)$} \\
\hline Hypertension & $330(76.2)$ \\
\hline Dyspnea & $166(38.3)$ \\
\hline Depression (diagnosis and/or treatment) & $154(35.6)$ \\
\hline Anxiety (diagnosis and/or treatment) & $145(33.5)$ \\
\hline ASCVD & $133(30.7)$ \\
\hline T2DM & $115(26.6)$ \\
\hline
\end{tabular}

Table 1 continued

\begin{tabular}{ll}
\hline & $\begin{array}{l}\text { Total } \\
(\boldsymbol{n}=433)\end{array}$ \\
\hline Smoking status $^{\mathrm{a}}, n(\%)$ & $122(28.2)$ \\
Current smoker & $279(64.4)$ \\
Former smoker & $15(3.5)$ \\
Never smoked/lives with smoker & $17(3.9)$ \\
Never smoked/no household smoke & 0 \\
Missing & $46.9(31.2)$, \\
Smoking pack years ${ }^{\mathrm{a}, \mathrm{e}}$, mean (SD), $n$ & 381 \\
Geographic region ${ }^{\mathrm{b}}, n$ (\%) & \\
Northeast & $77(17.8)$ \\
Midwest & $125(28.9)$ \\
South & $188(43.4)$ \\
West & $43(9.9)$ \\
\hline
\end{tabular}

Percentages were calculated based on respondents with available data

$A S C V D$ atherosclerotic cardiovascular disease, $C O P D$ chronic obstructive pulmonary disease, $S D$ standard deviation, $T 2 D M$ type 2 diabetes mellitus

${ }^{a}$ Survey-based; ${ }^{b}$ claim-based; ${ }^{c} 0.9 \%$ to $2.1 \%$ reported identification as American Native, Asian, Multi-racial, or other race; ${ }^{d}$ comorbidities with incidence $<20 \%$ not shown; ${ }^{e}$ number of cigarettes smoked per day ${ }^{*}$ number of years of smoking/20

Patient demographics and clinical characteristics are presented in Table 1. Over half of the patients were female $(59.8 \%)$, and the average age was 71.0 years. The majority had an education level of high school or less $(58.4 \%)$, annual household income $<\$ 50,000(79.2 \%)$, and were current or former smokers $(92.6 \%)$. There was a high incidence of comorbidities during the 12-month baseline period: all patients had at least one comorbidity, as measured by the Quan-Charlson comorbidity index, [19] with a mean (SD) baseline score of 2.2 (1.6), and with $36 \%$ of patients having a mean comorbidity score of $\geq 3$. A comparison of baseline demographics of respondents and non-respondents to the survey is shown in Supplementary Table S2. Respondents and non- 
respondents tended to be similar when compared by select demographic characteristics (age, gender, geographic region).

\section{COPD Burden of Illness}

Despite all patients receiving LAMA monotherapy, the majority reported a high COPD symptom burden; $85.5 \%$ and $39.0 \%$ had a CAT total

Table 2 COPD-related patient-reported outcomes

Total $(n=433)$

CAT total score, mean (SD)

$18.5(8.4)$

$\mathrm{CAT}^{\mathrm{a}}, n(\%)$

CAT total score $<10$

CAT total score $\geq 10$

CAT total score $10-20$

$201(46.4)$

CAT total score $21-30$

CAT total score $31-40$

$42(9.7)$

mMRC score, mean (SD)

$1.6(1.0)$

mMRC categories ${ }^{\mathrm{b}}, n$ (\%)

Low dyspnea severity (grades 0-1)

High dyspnea severity (grades 2-4)

EXACT total score, mean (SD)

$154(35.6)$

Less severe symptoms

$279(64.4)$

More severe symptoms

$$
279(64.4)
$$

PRO combinations, $n$ (\%)

Low CAT score/low mMRC score/low EXACT score

High CAT score/low mMRC score/low EXACT score

$61(14.1)$

Low CAT score/high mMRC score/low EXACT score

Low CAT score/low mMRC score/high EXACT score

High CAT score/high mMRC score/low EXACT score

High CAT score/low mMRC score/high EXACT score

$116(26.8)$

Low CAT score/high mMRC score/high EXACT score

$1(0.2)$

High CAT score/high mMRC score/high EXACT score

$155(35.8)$

CAT COPD Assessment Test, COPD chronic obstructive pulmonary disease, EXACT Exacerbations of Chronic Pulmonary Disease Tool, $m M R C$ modified Medical Research Council dyspnea scale, PRO patient-reported outcome, $S D$ standard deviation

${ }^{a}$ Higher CAT values indicate greater symptom burden; ${ }^{b}$ higher mMRC values indicate greater dyspnea; ${ }^{c}$ EXACT symptom categories: severe symptoms = having an EXACT score greater than the mean total score in the study sample, on at least 1 day; higher EXACT values indicate greater symptom severity 
score $\geq 10$ or $\geq 21$, respectively, and the mean (SD) overall CAT score was 18.5 (8.4). In addition, almost half of the patients $(45.5 \%)$ had high levels of dyspnea (mMRC grade 2-4); the mean (SD) mMRC score was 1.6 (1.0), and most patients experienced shortness of breath with less than strenuous exercise $(90.5 \%)$. Analysis of the EXACT daily diary scores showed that $64.4 \%$ of patients had more severe symptoms (relative to the mean total study sample score on at least 1 day) and the mean (SD) average EXACT total score was 37.1 (12.1) (Table 2).

Over one-third $(35.8 \%)$ of patients had a higher symptom burden on all three PRO measures (mMRC, CAT, and EXACT), and $71.6 \%$ reported high scores on $\geq 2$ COPDrelated PRO measures. By contrast, only $12.0 \%$ of patients experienced low symptom burden on all three measures (Table 2).

\section{All-Cause HCRU}

Patients were prescribed a mean (SD) of 12.8 (6.7) unique medications during the 12-month baseline period. Patients with more severe disease burden (CAT score $\geq 10$ ) were prescribed a statistically significantly higher number of unique medications than those with a low CAT score (CAT score < 10; Supplementary Table S3). All patients had $\geq 1$ all-cause ambulatory visits during the baseline period, with most patients having at least one visit to the physician's office (Supplementary Table S3). Nearly 1 in 4 patients experienced an inpatient hospitalization $(22.6 \%)$, with an average length of stay for inpatient admissions of 13 days. Nearly half $(45.3 \%)$ of patients had $\geq 1 \mathrm{ED}$ visit, and the average number of visits among those with any ED visit was 2.1 visits per person.

\section{COPD-Related HCRU}

Almost all patients (97.7\%) had $\geq 1$ COPDrelated ambulatory visits during the 12 -month baseline period, including $89.4 \%$ of patients requiring a physician office visit and $49.0 \%$ with at least 1 outpatient visit (Table 3). The proportion of patients with physician office visits was statistically significantly lower among patients with high disease burden compared with those with low disease burden as measured by total CAT score $(88.1 \%$ vs $96.8 \%, P=0.044)$. Of those patients with at least one physician office visit, patients with higher CAT scores required more visits than those with lower CAT scores [mean (SD) number of visits: $3.7(2.4)$ vs 3.2 (1.8), $P=0.035]$. No statistically significant difference was observed between the numbers of patients requiring outpatient visits.

A quarter $(25.4 \%)$ of patients had a COPD-related $\mathrm{ED}$ visit during the baseline period; the mean number of ED visits among these patients was 1.6 (Table 3). The proportion of patients with ED visits was statistically significantly higher among patients with high symptom burden (CAT score $\geq 10$ ) than those with low symptom burden (CAT score $<10 ; 27.6 \%$ vs $12.7 \%, P=0.012$ ). Overall, $21.3 \%$ of patients were hospitalized at least once for COPD; among these patients, the mean number of hospitalizations was 1.4 with an average duration of 13 days. Differences in the numbers of inpatient visits, and the mean duration of inpatient stays, between patients with low and high CAT total scores were not statistically significant.

\section{DISCUSSION}

In this claims-linked survey study assessing patient-reported symptoms and burden of illness among patients with COPD treated with LAMA monotherapy, COPD had a considerable impact on patient well-being and was associated with substantial resource burden. These results are consistent with observations from previous studies which have reported that patients receiving long-acting bronchodilator monotherapy continued to experience a high symptom burden, had recent exacerbations and exhibited poor QoL, and had a higher than average rate of physician interactions [9, 24]. The majority of patients in this study experienced substantial symptom burden as measured by multiple PROs; in particular, there were high levels of dyspnea, with almost half of the patients experiencing severe dyspnea using the definitions presented in the GOLD strategic report [2]. Dyspnea poses significant problems 
Table 3 Association between COPD-cause healthcare resource utilization during the 12-month baseline period and burden of illness

\begin{tabular}{|c|c|c|c|c|}
\hline & $\begin{array}{l}\text { Total } \\
(n=433)\end{array}$ & $\begin{array}{l}\text { Low impact } \\
\text { (CAT 0-9) } \\
(n=63)\end{array}$ & $\begin{array}{l}\text { High impact } \\
(\text { CAT 10-40) } \\
(n=370)\end{array}$ & $p$ value \\
\hline Number of pharmacy fills ${ }^{a}$, mean (SD) & $1.0(0.0)$ & $1.0(0.0)$ & $1.0(0.0)$ & - \\
\hline \multicolumn{5}{|l|}{ Ambulatory visits } \\
\hline Proportion of patients, $n(\%)$ & $423(97.7)$ & $63(100.0)$ & $360(97.3)$ & 0.370 \\
\hline Number, mean $(\mathrm{SD})$ & $5.0(4.1)$ & $4.7(2.8)$ & $5.0(4.3)$ & 0.502 \\
\hline Number among patients with $\geq 1$ visit, mean (SD) & $5.1(4.1)$ & $4.7(2.8)$ & $5.2(4.3)$ & 0.318 \\
\hline \multicolumn{5}{|l|}{ Office visits } \\
\hline Proportion of patients, $n(\%)$ & $387(89.4)$ & $61(96.8)$ & $326(88.1)$ & 0.044 \\
\hline Number, mean $(\mathrm{SD})$ & $3.3(2.5)$ & $3.1(1.8)$ & $3.3(2.6)$ & 0.416 \\
\hline Number among patients with $\geq 1$ visit, mean (SD) & $3.7(2.3)$ & $3.2(1.8)$ & $3.7(2.4)$ & 0.035 \\
\hline \multicolumn{5}{|l|}{ Outpatient visits } \\
\hline Proportion of patients, $n(\%)$ & $212(49.0)$ & $34(54.0)$ & $178(48.1)$ & 0.416 \\
\hline Number, mean $(S D)$ & $1.7(3.6)$ & $1.7(2.5)$ & $1.7(3.8)$ & 0.881 \\
\hline Number among patients with $\geq 1$ visit, mean (SD) & $3.5(4.5)$ & $3.1(2.6)$ & $3.6(4.8)$ & 0.396 \\
\hline \multicolumn{5}{|l|}{ ED visits } \\
\hline Proportion of patients, $n$ (\%) & $110(25.4)$ & $8(12.7)$ & $102(27.6)$ & 0.012 \\
\hline Number, mean $(S D)$ & $0.4(1.0)$ & $0.2(0.5)$ & $0.4(1.0)$ & 0.002 \\
\hline Number among patients with $\geq 1$ visit, mean $(S D)$ & $1.6(1.4)$ & $1.4(0.7)$ & $1.6(1.4)$ & 0.653 \\
\hline \multicolumn{5}{|l|}{ IP stays (all patients) } \\
\hline Proportion of patients, $n(\%)$ & $92(21.3)$ & $16(25.4)$ & $76(20.5)$ & 0.406 \\
\hline Number, mean $(\mathrm{SD})$ & $0.3(0.7)$ & $0.4(0.7)$ & $0.3(0.7)$ & 0.428 \\
\hline Duration, days, mean $(\mathrm{SD})$ & $2.8(9.9)$ & $6.5(21.1)$ & $2.1(6.2)$ & 0.108 \\
\hline \multicolumn{5}{|l|}{ IP stays (patients with $\geq 1$ admission) } \\
\hline Number, mean $(\mathrm{SD})$ & $1.4(0.7)$ & $1.4(0.7)$ & $1.4(0.8)$ & 0.937 \\
\hline Duration, days, mean (SD) & $13.1(18.2)$ & $25.6(36.2)$ & $10.4(10.1)$ & 0.117 \\
\hline
\end{tabular}

$C A T$ COPD Assessment Test, COPD chronic obstructive pulmonary disease, $E D$ emergency department, $I P$ inpatient, $S D$ standard deviation

${ }^{a}$ COPD-related treatment claims

for patients, not only in terms of day-to-day QoL but also as a marker of disease progression: for example, dyspnea is a predictor for hospitalization [25] and was found elsewhere to be more strongly correlated with 5-year survival rate than forced expiratory volume in $1 \mathrm{~s}$ [26].
The current analysis closely mirrored the GOLD strategy in identifying the impact of COPD in patients with a low and high level of symptoms as defined by a CAT score of $<10$ or $\geq 10$, respectively. In the cohort identified in this study, the vast majority of patients 
with COPD had a high level of symptoms. Consequently, future real world studies could plan to explore additional cut-off points in CAT score $\geq 10$ to gain additional insights on the level of symptoms likely to further extenuate any increased risk of HCRU.

In this study, patients utilized a wide range of healthcare resources requiring hospitalization and ED visits, as well as a range of ambulatory visits. The majority of patients $(97.7 \%)$ were seen by a healthcare professional for their COPD (office or outpatient visit) during the 12-month baseline period. A statistically significantly greater proportion of patients with lower CAT total scores $(<10)$ had a physician office visit compared with patients with higher CAT scores $(\geq 10)$. Conversely, patients with higher CAT scores had statistically significantly more ED visits, suggesting greater disease severity or suboptimal management, consistent with the greater symptom burden experienced by this group.

In view of the considerable symptom burden and resource use evident among patients treated with LAMA monotherapy in this study, it is possible that many of these patients could benefit from escalation of therapy. In accordance with the current GOLD recommendations, clinicians should consider the use of an additional bronchodilator such as LAMA/LABA combination therapy when a monotherapy bronchodilator does not provide adequate symptom control [2]. Multiple clinical trials and network meta-analyses have reported improved lung function and QoL outcomes with the use of LAMA/LABA combination therapy compared with long-acting bronchodilator monotherapy [27-34].

It should be noted that CAT, mMRC, and EXACT assess different aspects of COPD burden of illness, and it remains unclear which of these tools or combination of tools should be prioritized in assessment of patient symptoms. The current study was limited to patients receiving LAMA monotherapy and excluded all patients prescribed ICS or dual bronchodilators. The reasons why patients with poor disease control on monotherapy did not escalate to combination therapies were not evaluated. One possible reason might be an underestimation of the symptom burden by the physician, as identified by Mapel et al. [35] or poor communication of the symptom burden between patients and physicians.

We note that the study population is slightly older, has a higher proportion of female patients, and a lower percentage of smokers than are usually seen in COPD clinical trials [36]. In addition, a high proportion of patients have comorbidities, in particular those related to ASCVD, [36] therefore it is possible that dyspnea observed in these patients may not be due only to COPD.

Limitations of this study included those typically associated with claims-linked survey studies. Because claims data are collected for payment rather than research, this data source is associated with certain limitations: the presence of a claim for a filled prescription does not indicate that the medication was consumed or taken as prescribed, and medications filled over-the-counter or provided as samples by a physician were not captured. Additionally, the presence of a diagnosis code on a medical claim does not constitute conclusive evidence of the disease. Patients with a diagnosis of asthma were not excluded from the study; therefore, as no spirometry data were available to confirm the COPD diagnosis, it is possible that the diagnosis code may have been included as a rule-out criterion or incorrectly coded. To help address these limitations, multiple pharmacy claims and diagnosis codes were required for sample inclusion; the requirement for patients to have claims-based and self-reported treatment and multiple diagnosis codes for COPD at least 30 days apart ensured that a prevalent population of patients with COPD was included in the analysis. Patients were also required to report a healthcare provider COPD diagnosis and COPD treatment. The study is subject to limitations of survey data, including sampling error, coverage error, and measurement error. Finally, the study population comprised patients with commercial health plan coverage and MA enrollees, and therefore the results may not be generalizable to uninsured populations or more broadly to populations outside the USA.

\section{CONCLUSIONS}

While LAMA monotherapy has demonstrated efficacy and has been shown to reduce dyspnea, 
exacerbations, and hospitalizations in patients with COPD, [37] the results of this study demonstrate that a large proportion of patients receiving LAMA monotherapy still remain symptomatic. Escalation of therapy to a dual LAMA/ LABA combination may be indicated to reduce patient burden of illness and improve patient QoL, which may in turn reduce HCRU. Better utilization of PROs to understand symptom severity and disease burden in COPD may lead to improved treatment strategies and in turn to amelioration of disease burden and reduced HCRU. Physicians should therefore consider including questions or tools to measure symptom burden, such as the CAT or mMRC, as part of routine care for patients with COPD.

\section{ACKNOWLEDGMENTS}

The authors thank the participants of this study.

Funding. This study was funded by GlaxoSmithKline (GSK study number 205862 [HO-16-16642]). The funders of the study had a role in the study design, data analysis, data interpretation, and writing of the report. The article processing charges associated with this publication were funded by GSK. The study was conducted by Optum and funded by GSK. Employees of Optum were not paid for manuscript development. All authors had full access to the data in this study and take complete responsibility for the integrity of the data and accuracy of the data analysis. The corresponding author had the final responsibility to submit for publication and is the guarantor.

Medical Writing, Editorial, and Other Assistance. Editorial support (in the form of writing assistance, assembling tables and figures, collating author comments, grammatical editing and referencing) was provided by Elizabeth Jameson, PhD, at Fishawack Indicia Ltd, UK, and was funded by GSK.

Authorship. All named authors meet the International Committee of Medical Journal
Editors (ICMJE) criteria for authorship for this article, take responsibility for the integrity of the work, contributed to the writing and reviewing of the manuscript, and have given final approval for the version to be published.

Authorship Contributions. BH was involved in the conception/design of the study and analysis/interpretation of data. RHS was involved in the conception/design of the study and analysis/interpretation of data. AGH was involved in conception/design of the study, the acquisition of data and analysis/interpretation of data. BE was involved in the acquisition of data. JW (statistician) was involved in the acquisition of data and analysis/interpretation of data. RR was involved in the conception/design of the study and analysis/interpretation of data.

Disclosures. Beth Hahn is an employee of GSK and hold stocks/shares in GSK. Riju Ray is an employee of GSK and hold stocks/shares in GSK. Richard H Stanford is an employee of GSK and hold stocks/shares in GSK. Alyssa Goolsby Hunter is an employee of Optum, which was contracted by GSK to conduct the study. Alyssa Goolsby Hunter also owns stocks in Optum's parent company, United Health Group. Breanna Essoi is an employee of Optum, which was contracted by GSK to conduct the study. John White is an employee of Optum, which was contracted by GSK to conduct the study. Employees of Optum were not paid for manuscript development.

Compliance with Ethics Guidelines. The study was approved by the New England Institutional Review Board (NEIRB), on September 9, 2016 (IRB \#120160900). Data collection activities were initiated following all approvals. All procedures performed in studies involving human participants were in accordance with the ethical standards of the institutional and/or national research committee and with the 1964 Helsinki declaration and its later amendments or comparable ethical standards. Informed consent to take part in the study was implied by the return of study materials. 
Data Availability Statement. This study was a collaboration between GSK and Optum. GSK makes available anonymized individual participant data and associated documents from interventional clinical studies which evaluate medicines, upon approval of proposals submitted to www.clinicalstudydatarequest.com. To access data for other types of GSK sponsored research, for study documents without patientlevel data and for clinical studies not listed, please submit an enquiry via the website. The datasets analyzed during the current study are not publicly available. For this manuscript, the data is contained in a database owned by Optum and contains proprietary elements and, therefore, cannot be broadly disclosed or made publicly available at this time. The disclosure of this data to third-party clients assumes certain data security and privacy protocols are in place and that the third-party client has executed Optum's standard license agreement which includes restrictive covenants governing the use of the data.

Open Access. This article is distributed under the terms of the Creative Commons Attribution 4.0 International License (http:// creativecommons.org/licenses/by/4.0/), which permits unrestricted use, distribution, and reproduction in any medium, provided you give appropriate credit to the original author(s) and the source, provide a link to the Creative Commons license, and indicate if changes were made.

\section{REFERENCES}

1. Ehteshami-Afshar S, FitzGerald JM, Doyle-Waters MM, Sadatsafavi M. The global economic burden of asthma and chronic obstructive pulmonary disease. Int J Tuberc Lung Dis. 2016;20(1):11-23.

2. Global Initiative for Chronic Obstructive Lung Disease. Global Strategy for the Diagnosis, Management and Prevention of Chronic Obstructive Pulmonary Disease (2019 Report). http://goldcopd. org/gold-reports/. Accessed 14 February 2019.

3. National Center for Health Statistics. Health, United States; 2016. https://www.cdc.gov/nchs/hus/ index.htm. Accessed 28 September 2017.
4. Wheaton A, Cunningham T, Ford E, Croft J. Employment and activity limitations among adults with chronic obstructive pulmonary disease-United States, 2013. Morb Mortal Wkly Rep. 2015;64:289-95.

5. Lopez-Campos JL, Tan W, Soriano JB. Global burden of COPD. Respirology. 2016;21(1):14-23.

6. Cazzola M, Page CP, Calzetta L, Matera MG. Pharmacology and therapeutics of bronchodilators. Pharmacol Rev. 2012;64(3):450-504.

7. Tashkin DP, Cooper CB. The role of long-acting bronchodilators in the management of stable COPD. Chest J. 2004;125(1):249-59.

8. Tashkin DP, Ferguson GT. Combination bronchodilator therapy in the management of chronic obstructive pulmonary disease. Respir Res. 2013;14(1):49.

9. Dransfield MT, Bailey W, Crater G, Emmett A, O'Dell DM, Yawn B. Disease severity and symptoms among patients receiving monotherapy for COPD. Prim Care Respir J. 2011;20(1):46-53.

10. Kessler R, Partridge MR, Miravitlles M, Cazzola M, Vogelmeier C, Leynaud D, et al. Symptom variability in patients with severe COPD: a pan-European cross-sectional study. Eur Respir J. 2011;37(2):264-72.

11. Miravitlles M, Ribera A. Understanding the impact of symptoms on the burden of COPD. Respir Res. 2017;18(1):67.

12. Monteagudo M, Rodriguez-Blanco T, Llagostera M, Valero C, Bayona X, Ferrer M, et al. Factors associated with changes in quality of life of COPD patients: a prospective study in primary care. Respir Med. 2013;107(10):1589-97.

13. Donaldson GC, Seemungal TA, Bhowmik A, Wedzicha JA. Relationship between exacerbation frequency and lung function decline in chronic obstructive pulmonary disease. Thorax. 2002;57(10): 847-52.

14. Ding B, Small M, Bergstrom G, Holmgren U. COPD symptom burden: impact on health care resource utilization, and work and activity impairment. Int J Chron Obstruct Pulmon Dis. 2017;12:677-89.

15. Foo J, Landis SH, Maskell J, Oh YM, van der Molen $\mathrm{T}$, Han MK, et al. Continuing to confront COPD international patient survey: economic impact of COPD in 12 countries. PLoS One. 2016;11(4):e0152618.

16. Dillman D, Smyth J, Christian L. Internet, mail, and mixed-mode surveys The Tailored Design Method. 4th ed. New york: Wiley; 2014. 
17. Centers for Disease Control and Prevention. Indicator definitions-chronic obstructive pulmonary disease. https://www.cdc.gov/cdi/definitions/chronicobstructive.html. Accessed August 1st 2018.

18. Hillas G, Perlikos F, Tsiligianni I, Tzanakis N. Managing comorbidities in COPD. Int J Chron Obstruct Pulmon Dis. 2015;10:95-109.

19. Quan H, Li B, Couris CM, Fushimi K, Graham P, Hider $P$, et al. Updating and validating the Charlson comorbidity index and score for risk adjustment in hospital discharge abstracts using data from six countries. Am J Epidemiol. 2011;173(6):676-82.

20. Jones PW, Harding G, Berry P, Wiklund I, Chen WH, Kline Leidy N. Development and first validation of the COPD assessment test. Eur Respir J. 2009;34(3):648-54.

21. Leidy NK, Wilcox TK, Jones PW, Roberts L, Powers $\mathrm{JH}$, Sethi S, et al. Standardizing measurement of chronic obstructive pulmonary disease exacerbations. Reliability and validity of a patient-reported diary. Am J Respir Crit Care Med. 2011;183(3):323-9.

22. Jones PW, Tabberer M, Chen WH. Creating scenarios of the impact of COPD and their relationship to COPD assessment test (CAT) scores. BMC Pulm Med. 2011;11:42.

23. The American Association for Public Opinion Research. Standard definitions: final dispositions of case codes and outcome rates for surveys. https:// www.aapor.org/AAPOR_Main/media/MainSiteFiles/ Standard-Definitions2015_8thEd.pdf. Accessed December 7th 18.

24. Edwards SC, Fairbrother SE, Scowcroft A, Chiu G, Ternouth A, Lipworth BJ. The burden of chronic obstructive pulmonary disease associated with maintenance monotherapy in the UK. Int J Chron Obstruct Pulmon Dis. 2016;11:2851-8.

25. Ong KC, Earnest A, Lu SJ. A multidimensional grading system (BODE index) as predictor of hospitalization for COPD. Chest. 2005;128(6):3810-6.

26. Nishimura K, Izumi T, Tsukino M, Oga T. Dyspnea is a better predictor of 5-year survival than airway obstruction in patients with COPD. Chest. 2002;121(5):1434-40.

27. Tashkin DP, Pearle J, Iezzoni D, Varghese ST. Formoterol and tiotropium compared with tiotropium alone for treatment of COPD. COPD. 2009;6(1):17-25.
28. Bateman ED, Ferguson GT, Barnes N, Gallagher N, Green Y, Henley M, et al. Dual bronchodilation with QVA149 versus single bronchodilator therapy: the SHINE study. Eur Respir J. 2013;42(6):1484-94.

29. Calzetta L, Rogliani P, Matera MG, Cazzola M. A Systematic review with meta-analysis of dual bronchodilation with LAMA/LABA for the treatment of stable COPD. Chest. 2016;149(5):1181-96.

30. Decramer M, Anzueto A, Kerwin E, Kaelin T, Richard N, Crater G, et al. Efficacy and safety of umeclidinium plus vilanterol versus tiotropium, vilanterol, or umeclidinium monotherapies over 24 weeks in patients with chronic obstructive pulmonary disease: results from two multicentre, blinded, randomised controlled trials. Lancet Respir Med. 2014;2(6):472-86.

31. Maleki-Yazdi, Kaelin T, Richard N, Zvarich M, Church A. Efficacy and safety of umeclidinium/vilanterol $62.5 / 25 \mathrm{mcg}$ and tiotropium $18 \mathrm{mcg}$ in chronic obstructive pulmonary disease: results of a 24-week randomized controlled trial. Respir Med. 2014;108(12):1752-60.

32. Oba Y, Sarva ST, Dias S. Efficacy and safety of longacting beta-agonist/long-acting muscarinic antagonist combinations in COPD: a network meta-analysis. Thorax. 2016;71(1):15-25.

33. van Noord JA, Aumann JL, Janssens E, Smeets JJ, Zaagsma J, Mueller A, et al. Combining tiotropium and salmeterol in COPD: effects on airflow obstruction and symptoms. Respir Med. 2010;104(7):995-1004.

34. Sion KYJ, Huisman EL, Punekar YS, Naya I, Ismaila AS. A network meta-analysis of long-acting muscarinic antagonist (LAMA) and long-acting $\beta 2$-agonist (LABA) combinations in COPD. Pulm Ther. 2017;3(2):297-316.

35. Mapel DW, Dalal AA, Johnson P, Becker L, Hunter AG. A clinical study of COPD severity assessment by primary care physicians and their patients compared with spirometry. Am J Med. 2015;128(6):629-37.

36. Miravitlles M, Price D, Rabe KF, Schmidt H, Metzdorf N, Celli B. Comorbidities of patients in tiotropium clinical trials: comparison with observational studies of patients with chronic obstructive pulmonary disease. Int $\mathrm{J}$ Chron Obstruct Pulmon Dis. 2015;10:549-64.

37. Vogelmeier CHB, Glaab T, Schmidt H, Rutten-van Mölken MBK, Rabe K, Fabbri L. Tiotropium versus salmeterol for the prevention of exacerbations of COPD. N Engl J Med. 2011;364(12):1093-103. 